\title{
HIV and Autoimmune Hepatitis: A Case Series and Literature Review
}

\section{Samir Parekh, Zachary Spiritos, Paul Reynolds, Samir Parekh, Adam Perricone and Brian Quigley}

${ }^{1}$ Department of Medicine, Emory University School of Medicine, Atlanta, GA, USA

${ }^{2}$ Department of Medicine, Division of Digestive Diseases, Emory University School of Medicine, Atlanta, GA, USA

${ }^{3}$ Department of Pathology, Emory University School of Medicine, Atlanta GA, USA

Corresponding author: Parekh S, Assistant Professor of Medicine, Department of Medicine, Emory University School of Medicine, Atlanta, GA, USA, Tel: 404-778-3986, Fax: 404-778-2925; E-mail: smparek@emory.edu

Received Date: January 15, 2017; Accepted Date: February 15, 2017; Published Date: February 21, 2017

Copyright: (C) 2017 Parekh S, et al. This is an open-access article distributed under the terms of the Creative Commons Attribution License, which permits unrestricted use, distribution, and reproduction in any medium, provided the original author and source are credited.

Citation: Parekh S, Spiritos Z, Reynolds P, et al. HIV and Autoimmune Hepatitis: A Case Series and Literature Review. J Biomedical Sci. 2017, 6:2.

\section{Abstract}

Liver disease is the leading cause of non-AIDS related morbidity and mortality in human immunodeficiency virus (HIV) infected patients. There are many causes of liver disease in these patients, most commonly co-infection with viral hepatitis or alcoholic liver disease. A far less commonly described entity is autoimmune hepatitis (AIH) in HIV patients. The relationship between HIV and autoimmune diseases is well-described in a few conditions such as systemic lupus erythematosus and diffuse infiltrative lymphocytosis syndrome; however, patients with HIV who subsequently develop autoimmune hepatitis (AIH) has rarely been described in the existing literature. Managing these coexisting morbidities requires careful monitoring, as treating $\mathrm{AlH}$ requires the further immunosuppression of an HIV-infected individual. Herein, we present two patients who were diagnosed with and treated for AlH while receiving concurrent highly active anti-retroviral therapy. This case series provides treatment outcome data for a situation that has heretofore been rarely reported.

\section{Keywords: HIV; Autoimmune hepatitis; liver biopsy}

\section{Introduction}

Autoimmune Hepatitis (AIH) is a rare disease that is caused by circulating antibodies that cause inflammation and hepatocellular injury. Diagnosis is made through abnormal liver enzymes, detection of circulating autoantibodies, liver biopsy, and the exclusion of other causes of hepatotoxicity including infections and drug-induced liver damage [1]. The International Autoimmune Hepatitis Group developed the original diagnostic criteria in 1999 which incorporated liver histopathology, serum studies, viral markers, and other etiological factors into a scoring system. A more simplified scoring system was created 2008 which focuses on liver histology and serum autoantibody which is shown is Table 1 [2].

AlH is considered an autoimmune disorder and hepatic injury is due to a sensitized but reactive immune system. There have been a growing number of cases that describe the co-existence of HIV and AIH. The association between autoimmune disorders and HIV is well described, although not completely understood. The most well studied autoimmune disorders in HIV-infected patients include Systemic Lupus Erythematosus (SLE), Immune Thrombocytopenic Purpura (ITP), vasculitis, polymyositis, dermatomyositis, Graves disease, and primary biliary cirrhosis [3].

Table 1 Simplified diagnostic criteria (2008) of the international autoimmune hepatitis group [2].

\begin{tabular}{|c|c|c|}
\hline & & Points \\
\hline \multirow[t]{3}{*}{ Autoantibodies } & ANA, SMA, OR LKM>1: 40 & 1 \\
\hline & ANA, SMA, OR LKM>1: 80 & 2 \\
\hline & SLA/LP positive (>20units) & \\
\hline \multirow[t]{2}{*}{$\lg$} & Upper limit of normal & 1 \\
\hline & $>1.10 x$ the upper limit of normal & 2 \\
\hline \multirow[t]{6}{*}{ Liver Histology } & Compatible with $\mathrm{AlH}$ & 1 \\
\hline & $\begin{array}{l}\text { Chronic hepatitis with lymphocytic } \\
\text { infiltrations without features considered } \\
\text { typical }\end{array}$ & \\
\hline & Typical for AlH & 2 \\
\hline & $\begin{array}{l}\text { Interface hepatitis; lymphocytic/ } \\
\text { lymphoplasmocytic infiltrates in the portal } \\
\text { tracts }\end{array}$ & \\
\hline & $\begin{array}{l}\text { Emperipolesis: active penetrations by } \\
\text { one cell into and through larger cell }\end{array}$ & \\
\hline & Hepatic rosette formation & \\
\hline \multirow{2}{*}{$\begin{array}{l}\text { Absence of viral } \\
\text { hepatitis }\end{array}$} & No & 0 \\
\hline & Yes & 2 \\
\hline \multirow[t]{2}{*}{ Points } & Points>6: Probable AlH & \\
\hline & Points>7: Definite AlH & \\
\hline
\end{tabular}

Many of these autoimmune diseases are treated based on their underlying cause. For example, polymyositis, psoriasis, and Diffuse Infiltrative Lymphocytosis Syndrome (DILS) are due to proliferation of CD8 T-cells which can occur during the early 
stages of HIV-induced immunosuppression [4]. The treatment for these autoimmune disorders is antiretroviral therapy; however other autoimmune disorders in HIV patients, such as SLE and Grave's disease, require treatment with immunomodulators or glucocorticoids.

\section{Case Patient \#1}

A 21-year-old male with a past medical history of Grave's disease presented to a hospital with a 3-week history of jaundice and fatigue. He also reported subjective dark urine, anorexia, and lethargy over this time period. On exam he had bitemporal wasting, icteric sclera, a tender abdomen, and asterixis without evidence of encephalopathy. He was not on any medications but endorsed routine intravenous drug use.

Initial laboratory values were significant for transaminitis with AST/ALT of 2499/2088 U/L, INR 1.82 and a total bilirubin of 24.3 $\mathrm{mg} / \mathrm{dL}$. An abdominal ultrasound showed mild hepatomegaly. He was diagnosed at that time with HIV, and he had a CD4 count of $753 \mathrm{cell} / \mathrm{mL}$ with viral load of 7900 copies $/ \mathrm{mL}$. There was concern for autoimmune or viral hepatitis and follow-up serologies were significant for an IgG level of 2060 cells $/ \mathrm{mL}$. ANA, ASMA, and a hepatitis panel were negative. An anti-LKM1 was not checked.

The medical team pursued a liver biopsy which showed interface hepatitis with lymphoplasmocytic infiltrate compatible with AIH (Figure 1). By the simplified diagnostic criteria for AlH he had a probable diagnosis of $\mathrm{AlH}$. After the biopsy, he was started on prednisone $60 \mathrm{mg}$ daily. He was transitioned to prednisone $40 \mathrm{mg}$ daily as an outpatient and simultaneously started on emtricitabine, tenofovir, elvitegravir and cobicistat (Stribild). One month after starting prednisone therapy his transaminases normalized and one month later his bilirubin and INR normalized. His gastroenterologist wanted to transition him to 6-mercaptopurine; however, he was lost to follow up due to incarceration.

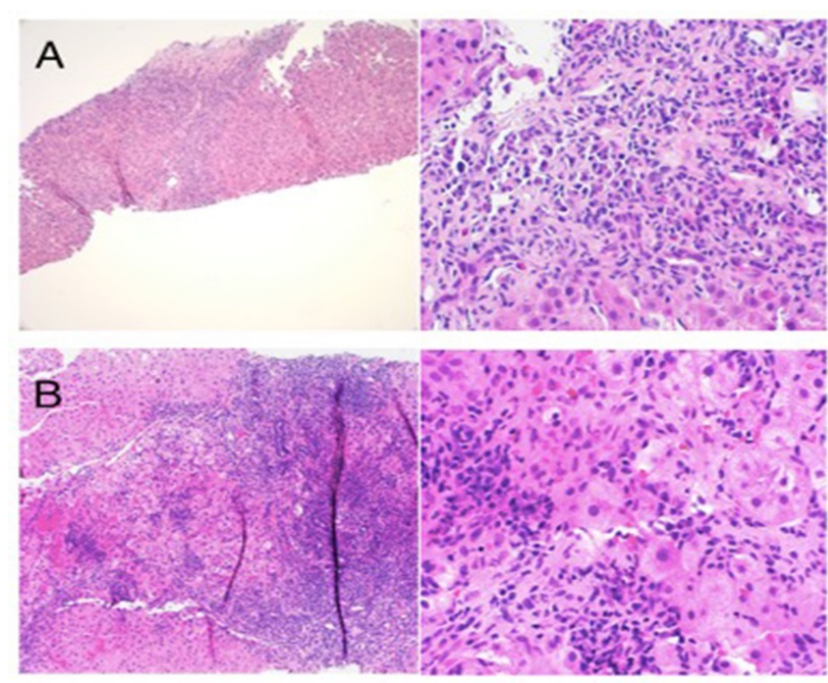

Figure $1 \mathrm{~A}$. Liver biopsy from case patient \#1.
After 3-months he was released from prison and at that point he saw his outpatient infectious disease physician who noted that he had been off all medications for the past 3-months. Laboratory tests revealed that he re-developed transaminitis (AST 82, ALT 32) without disruption in hepatic synthetic dysfunction. He was re-started on HAART therapy but never followed-up with either infectious disease or gastroenterology.

\section{Case Patient \#2}

A 59-year-old African-American female with HIV, not on antiretroviral therapy, presented to her outpatient infectious disease physician complaining of parotid gland enlargement and a dry mouth. Her CD4 count on presentation was 137 cells $/ \mathrm{mL}$. She tested positive for anti-Ro/SSA and anti-La/SSB antibodies and there was concern for AIDS associated DILS. She was started on efavirenz, emtricitabine and tenofovir disoproxil fumarate (Atripla).

Four months later she developed polyarthritis involving her bilateral hands, right hip, right ankle, and right knee. She had a positive ANA screen, positive anti-smooth muscle antibody titer $1: 80$, and a mild transaminitis. She was diagnosed with lupus and started on hydroxychloroquine $400 \mathrm{mg}$ daily and prednisone $5 \mathrm{mg}$ twice a day.

Despite immunosuppressive therapy and an increased CD4 count to 504 cells $/ \mathrm{mL}$, she developed significant fatigue and weight loss over the next 3 months. Follow-up serology showed worsening transaminitis with an AST/ALT of 215/156 U/L. A viral hepatitis panel was negative. Diagnostic considerations included drug-induced liver disease (DILI) and autoimmune hepatitis. DILI was thought less likely as the transaminitis preceded hydroxychloroquine therapy, however hydroxychloroquine was discontinued anyway.

Liver biopsy showed lymphoplasmocytic infiltrate in the portal tracts and rosette formation typical for AIH (Figures 1 and 2). By the simplified diagnostic criteria for $\mathrm{AlH}$ she had a definite diagnosis of $\mathrm{AlH}$. The prednisone dose was increased from $5 \mathrm{mg}$ daily to $10 \mathrm{mg}$ twice daily and her AST/ALT improved to $99 / 88$ $\mathrm{U} / \mathrm{L}$ two months later. Azathioprine $50 \mathrm{mg}$ daily was added, and her AST/ALT continued to improve to $49 / 50 \mathrm{U} / \mathrm{L}$. Clinically she reported no further weight loss or fatigue.

Eventually her prednisone was decreased to $5 \mathrm{mg}$ twice a day without recurrence of her disease. She continued azathioprine $50 \mathrm{mg}$ daily and re-started hydroxycholorquine $400 \mathrm{mg}$ daily. The patient is currently doing well with normal liver enzymes and a CD4 count above 500 cells $/ \mathrm{mL}$.

On left, fibrous septum containing a dense lymphoplasmacytic inflammatory infiltrate with prominent interface and lobular activity. 100x; hematoxylin and eosin. On right, dense plasma cell-rich infiltrate and an area of hepatocyte drop-out at the interface. 400x; hematoxylin and eosin. Biopsy is compatible withautoimmune hepatitis.B. Liver biopsy from case patient \#2. On left, dense portal lymphoplasmacytic inflammation with prominent interface and lobular activity. 100x; hematoxylin and eosin. On right, lobular lymphoplasmacytic inflammation with 
hepatocyte rosette formation. 400x; hematoxylin and eosin. Biopsy is typical for autoimmune hepatitis

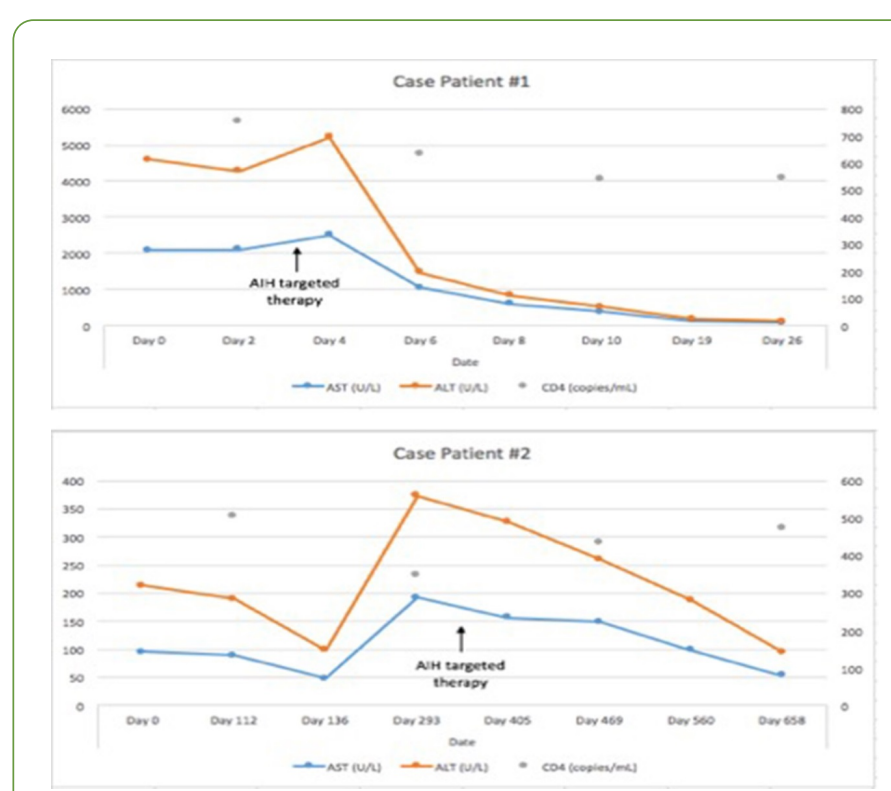

Figure $2 \mathrm{~A}$ timeline that plots patient liver function tests in relationship to initiation of autoimmune hepatitis (AIH) targeted therapy. Both patients were started on prednisone. Patient CD4 counts (cells $/ \mathrm{mL}$ ) are also shown.

\section{Discussion}

Liver disease is the most common cause of non-AIDS related morbidity and mortality in HIV patients [1], which is due in part to co-infection with hepatitis $B / C$ and increased use of alcohol in this population [4]. Additionally, certain antiretroviral therapy can have hepatotoxic side effects, which can range from asymptomatic transaminitis to fulminant liver failure [1] Autoimmune hepatitis is an especially difficult diagnosis to make in an HIV-infected patient due to the numerous potential causes of liver injury in these patients [4] As seen in these two patients, histology is critical in distinguishing AlH from other pathologies.

To date, there have been limited reports in the medical literature of HIV-infected patients with AlH. There is scant data on this patient cohort due to several factors. AlH is a rare disease with a mean incidence of 1-2 per 100,000 persons [1]. Patients with HIV not on anti-retroviral therapy who develop AIDS will not be able to mount the immune response to develop an autoimmune process. Additionally, HIV patients have other, more common reasons to develop liver injury such as medication toxicity, alcoholic hepatitis, viral hepatitis, nonalcoholic fatty liver disease or AIDS cholangiopathy. Therefore a thorough and proper work-up with a liver biopsy may not be performed because the diagnosis is not considered or the patient expires before diagnostic testing is finished.

Table 2 A review of the existing literature on patients with HIV who developed AIH. CD count is in cells/microliter and viral load is in copies/microliter. *Viral load.

\begin{tabular}{|c|c|c|c|c|c|c|}
\hline Age & Gender & Presentation & $\begin{array}{l}\text { Clinical } \\
\text { Response to } \\
\text { HAART? }\end{array}$ & Treatment & Outcome & $\begin{array}{l}\text { CD4/VL* at time of AlH } \\
\text { treatment }\end{array}$ \\
\hline 29 & Male & Elevated LFT's & No & None & LFT's improved & $174 / 27732$ \\
\hline 45 & Female & Elevated LFT's & No & Prednisone, Azathiprine & LFT's improved & 297/undetectable \\
\hline 65 & Female & Elevated LFT's & No & $\begin{array}{l}\text { Prednisone, } \\
\text { Mycophenolic acid }\end{array}$ & LFT's improved & 922/undetectable \\
\hline 44 & Female & Elevated LFT's & No & Prednisone, Azathiprine & LFT's improved & 526/undetectable \\
\hline 49 & Male & Elevated LFT's & No & Prednisone, Azathiprine & $\begin{array}{l}\text { LFT's improved, expired } \\
\text { due to opportunistic } \\
\text { diseases }\end{array}$ & $285 / 69,318$ \\
\hline 56 & Female & Elevated LFT's & No & $\begin{array}{l}\text { Prednisone, } \\
\text { Mercaptopurine }\end{array}$ & $\begin{array}{l}\text { Developed Burkitt's } \\
\text { lymphoma and expired }\end{array}$ & $331 / 232,732$ \\
\hline 42 & Female & $\begin{array}{l}\text { RUQ pain, night } \\
\text { sweats }\end{array}$ & No & Prednisone & LFT's improved & 232/undetectable \\
\hline 21 & Male & Lethargy, dark urine & No & Prednisone & LFT's improved & $753 / 7900$ \\
\hline 59 & Female & Elevated LFT's & No & Prednisone, Azathiprine & LFT's improved & 483/undetectable \\
\hline
\end{tabular}

The demographic information, HIV-status, and response to immunotherapy of the data on these patients is described in Table 2. In the cases reported, there is a predominance of women who have been found to develop AlH [5-8]. The diagnosis of AIH in HIV positive individuals was made at an average age or 45 years old, with a range of 21-59. Seven of the nine patients presented with asymptomatic elevation in their liver function tests. No patient had a clinical or serologic improvement in their transaminases with antiretroviral therapy alone. Two patients died from opportunistic diseases. Patients with low or undetectable viral loads all had favorable outcomes. There were four patients with detectable viral loads at time of treatment for $\mathrm{AlH}$; two improved with therapy while the other two died of AIDS-related illness. The two patients that died had 
markedly higher viral loads with a mean of 151,025 copies $/ \mathrm{mL}$ than those patients that survived who had a mean viral load of 21,776 copies/mL.

Diseases such as DILS, cryoglobulinemia, and psoriasis in HIVinfected patients have a clear relationship with HIV that responds well to antiretroviral therapy $[5,9]$ However other autoimmune diseases where the relationship to HIV is not well understood, may not respond as predictably. Based on these cases and the published literature, it seems that AIH and HIV are mutually exclusive diseases.

That being said, it is unclear whether initiation of HAART therapy can unmask a preexisting $\mathrm{AlH}$. Other autoimmune diseases such as sarcoidosis have been known to paradoxically worsen after immune reconstitution as part of an immune reconstitution inflammatory syndrome (IRIS) [10]. A diagnosis of IRIS requires worsening of a pre-existing or unrecognized condition during immunologic recovery. There should be a cause-and-effect relationship between initiation of HAART and manifestation of disease [11]. One prospective study found that patients with low pre-treatment CD4 counts (less than 100 cells $/ \mathrm{mL}$ ) developed IRIS typically within 22 to 99 days after initiating HAART $[11,12]$. The second case patient developed transaminitis 4 months after she started Atripla when her CD4 count was greater than 250 cells/mL. Her pre-treatment CD4 nadir was 137 cells $/ \mathrm{mL}$.

Classifying $\mathrm{AIH}$ as an IRIS-related illness has prognostic and therapeutic implications. The use of prednisone in HIV patients with suspected IRIS puts them at risk for proliferation of Kaposi's sarcoma (KS). In vitro studies suggest that AIDS-KS cells have high levels of glucocorticoid receptor proteins. Retrospective analysis has confirmed steroid use as a risk factor for KS associated mortality $[13,14]$. Therefore, physicians should use caution when treating patients for AlH-associated IRIS with prednisone who have a history of HIV-associated Kaposi' sarcoma.

Whether or not AIH-associated IRIS is a discrete entity, patients with HIV who develop AIH should be treated with prednisone rather than HAART monotherapy. However, based on the limited literature available, it is possible that above a certain viral load threshold glucocorticoid treatment leads to a higher mortality risk. The only poor prognostic factor identified to date has been an elevated viral load. Therefore, practitioners should use caution when treating $\mathrm{AlH}$ in patients that do not have virologic response to antiretroviral therapy.

In conclusion, $\mathrm{AlH}$ in patients with HIV is a rare but increasingly recognized entity which requires careful clinical decision-making in both its diagnosis and treatment. AlH should be in the differential diagnosis when evaluating a patient with elevated liver enzymes, and further case series may help delineate the optimal therapeutic approach in this special population.

\section{References}

1. Makol A, Watt K, Chowdhary V (2010) Autoimmune Hepatitis: A Review of Current Diagnosis and Treatment. Hepat Res Treat 26: 619-627.

2. Hennes EM, Zeniya M, Czaja AJ, Parés A, Dalekos GN, et al. (2008) Simplified criteria for the diagnosis of autoimmune hepatitis. Hepatology. 48: 169-176.

3. Zandman-Goddard G, Shoenfeld Y (2002) HIV and autoimmunity. Autoimmun Rev 1: 329-337.

4. Rosenbloom MJ, Sullivan EV, Sassoon SA, O'Reillt A, Fama R, et al. (2007) Alcoholism, HIV infection, and their comorbidity: factors affecting self-rated health-related quality of life. J Stud Alcohol Drugs. 68: 115-125.

5. Puius Y, Dove L, Brust D, Shah D, Lefkowitch JH (2008) Three Cases of Autoimmune Hepatitis in HIV-Infected Patients. J Clin Gastroenterol 42: 425-429.

6. O'Leary JG, Zachary K, Misdraji J, Chung RT (2008) De Novo Autoimmune Hepatitis during Immune Reconstitution in an HIVInfected Patient Receiving Highly Active Antiretroviral Therapy. Clin Infect Dis 46: 12-14.

7. Wan DW, Marks K, Yantiss RK, Talal AH (2009) Autoimmune Hepatitis in the HIV-Infected Patient: A Therapeutic Dilemma. AIDS Patient Care STDS 23: 407-413.

8. Daas H, Khatib R, Nasser H, Kamran F, Higgins M, et al. (2011) Human immunodeficiency virus infection and autoimmune hepatitis during highly active anti-retroviral treatment: a case report and review of the literature. J Med Case Reports 5: 133.

9. Walker UA, Tyndall A, Daikeler T (2008) Rheumatic conditions in human immunodeficiency virus infection. Rheumatology (Oxford) 47: 952-959.

10. Miranda EJ, Leite OH, Duarte MI (2001) Immune reconstitution inflammatory syndrome associated with pulmonary sarcoidosis in an HIV-infected patient: an immunohistochemical study. Braz J Infect Dis 15: 601-606.

11. Grant PM, Komarow L, Andersen J, Sereti I, Pahwa S, et al. (2010) Risk factor analyses for immune reconstitution inflammatory syndrome in a randomized study of early vs. deferred ART during an opportunistic infection. PLoS One 5: e11416.

12. Murdoch DM, Venter WD, Feldman C, Van Rie A (2008) Incidence and risk factors for the immune reconstitution inflammatory syndrome in HIV patients in South Africa: a prospective study. AIDS 22: 601.

13. Fernandez-Sanchez $M$, Iglesias $M C$, Ablanedo-Terrazas $Y$, Ormsby CY, Alvarado-de la Barrera C, et al. (2016) Steroids are a risk factor for Kaposi's sarcoma-immune reconstitution inflammatory syndrome and mortality in HIV infection. AIDS 30: 909-914.

14. Price JC, Thio CL (2010) Liver Disease in the HIV-Infected Individual. Clin Gastroenterol Hepatol 8: 1002-1012. 